\title{
A Literature Review of the Pharmacokinetics, Pharmacodynamics, and Possible Uses of
}

\section{Spironolactone}

\section{JAHIN ALI KHAN}

Department of Psychology, University of Toronto Scarborough, Canada

\section{Abstract}

This literature review aims to delineate the evolution of Spironolactone (SL), a multi-use drug, by providing an overview of what is known about its pharmacology and effects, as well as identifying future directions of research. SL is an antimineralocorticoid derived from progesterone and was therefore developed as a diuretic for hypertension and edema treatment. As a prodrug, its effects are largely mediated by its metabolites, 7athiomethylspironolactone and canrenone, which are ultimately eliminated through the urine. Later on, it was discovered that $\mathrm{SL}$ also exhibits moderate antiandrogenic activity due to its structural similarity to progesterone, allowing it to be used as an off-label treatment for hyperandrogenism and its associated symptoms, such as hirsutism and acne, as well as for transgender therapy. As researchers continue to elucidate the role of mineralocorticoid receptors in cognition and behaviour, new possibilities for $S L$ as an anxiolytic may also emerge in the future. With all that being said, SL's sexual side-effects, especially in males, continue to limit its various applications.

Keywords: pharmacology, antimineralocorticoid, antiandrogen

\section{Introduction}

Spironolactone (SL) is primarily an antimineralocorticoid and secondarily an antiandrogen (Sica, 2005). Due to this dualism, SL is prescribed to treat a variety of conditions associated with fluid retention (Schrier et al., 2010) and hormone imbalances (Voegli et al., 2009), and is used in transgender therapy as well (Angus et al., 2019). Now, research is shifting from the physiological effects of
SL to its cognitive effects, with potential implications for clinical treatment (Otte et al., 2007). Broadly, this literature review aims to delineate the evolution of SL by providing an overview of what is known about the drug's pharmacology, as well as identifying future directions of study. This paper begins with an explanation of SL's history, describes its pharmacokinetics and dynamics, and finally discusses its current 
and possible effects on cognition and behaviour.

\section{History}

As described in a review by Kolkhof \& Barfacker (2017), antimineralocorticoids consist of a sub-class of drugs called spirolactones, which are steroids that have $y$-lactone or $y$-hydroxy acid function at C17. These steroids are lab-made derivatives of the hormone, progesterone, and were developed in the 1950s upon discovering that progesterone acts as a natriuretic in dogs. SL, trade name "Aldactone," was the first spirolactone and therefore the first antimineralocorticoid to be marketed. It was synthesized by taking an analog, SC-5233, and dehydrogenating its double bonds and adding a 7aacetylthio group to increase oral bioavailability and potency. With approval from the U.S Food and Drug Administration, $S L$ was launched on the market in 1960 as a diuretic for hypertension and edema treatment (Kolkhof \& Barfacker, 2017). However, the drug was later found to have sexual sideeffects, such as impotence and painful gynecomastia in men and menstrual disturbances in women (Menard, 2004). Scientists discovered that these unintended side-effects occur because SL has structural similarity to progesterone and can thereby displace androgens and bind to their receptors (Menard, 2004). Regardless, the World Health Organization continues to list $S L$ as a core diuretic and core drug for heart failure (WHO, 2019). Due to its antiandrogenic activity, SL continues to be used off-label as a treatment for hyperandrogenism as well (Voegli et al., 2009). Today, scientists are also investigating SL's effects on cognition and anxiety (Otte et al., 2007), after it was discovered that there are mineralocorticoid receptors (MRs) in the brain.

\section{Pharmcokinetics of $S L$}

Spironolactone (SL) is an orally administered prodrug (Janowski et al., 1996), and $80-90 \%$ of it is absorbed through the gastrointestinal tract (Sica, 2005). Absorption increases further when $\mathrm{SL}$ is ingested with food, possibly due to a food-induced decrease in first-pass metabolism (Overdiek \& Merkus, 1986). Once in the liver, SL is largely and rapidly bio-transformed into 10 metabolites. The two main, physiologically active metabolites are 7athiomethylspironolactone, also known as 7a-TMS, and canrenone, otherwise known as CAN (Janowski et al., 1996). To produce $7 a-T M S, S L$ is first hydrolyzed at C7 to $7 a-$ TS, and then its thiol group is methylated. $7 a-T M S$ may then be converted to CAN through s-oxygenation followed by sulfoxide elimination (Cashman \& Pena, 1989). Because it is rapidly metabolized, $\mathrm{SL}$ has a half-life of only 1.4 hours in healthy participants, while $7 a-T M S$ and CAN have longer half-lives at 13.8 and 16.5 hours, respectively. This suggests that $\mathrm{SL}$ is a prodrug, meaning its effects are 
largely mediated by its metabolites, which take 8 days on a $100 \mathrm{mg} /$ day dose to achieve steady-state levels (Gardiner et al., 1989).

Once in the bloodstream, $88 \%$ of $\mathrm{SL}$ and $99.2 \%$ of CAN exhibit non-specific binding to plasma proteins, which decreases their bioavailabilities. Specifically, SL binds in almost equal amounts to albumin and a1acid glycoprotein, whereas canrenone binds only to albumin given the structural differences (Takamura et al., 1997). The available $S L$ and its metabolites can then bind to mineralocorticoid receptors (MRs) in the kidney (Schrier et al., 2010) and blood vessels (Nishizaka et al., 2004). Because of SL's lipophilic steroid base, they are also able to diffuse across the blood-brain barrier to MRs in the hippocampus (Otte et al., 2007). Ultimately, the active metabolites are eliminated through the urine or, to a lesser extent, through the feces via biliary excretion (Abshagen et al., 1977).

\section{Pharmcodynamics of SL}

$\mathrm{SL}$ is mainly a competitive mineralocorticoid receptor (MR) antagonist (Sica, 2005). These receptors are widely distributed and act as transcriptional regulators (de Kloet et al., 2005). At renal MRs, SL prevents the hormone, aldosterone, from binding and exerting its effects on fluid and nutrient balance (Schrier et al., 2010). Aldosterone is normally produced by the adrenal glands in response to reductions in blood volume, hyponatremia, or hyperkalemia, to restore homeostasis (Harris et al., 2003).

Upon binding to renal MRs, aldosterone stimulates nuclear protein synthesis, resulting in an increase in epithelial sodium channels (ENaC), sodium-potassium $(\mathrm{Na}+/ \mathrm{K}+)$ pumps, and epithelial renal outer medullary potassium (RomK) channels. These channels and pumps work together to move sodium and water into extracellular fluid (ECF) and potassium into the kidney lumen. Sodium and water are therefore retained in ECF and the blood, while potassium is excreted through whatever little urine there is (Schrier et al., 2010). And so, by blocking aldosterone from binding, SL prevents $\mathrm{ENaC}, \mathrm{Na}+\mathrm{K}+$ pump, and ROMK synthesis, which consequently reduces water and sodium reabsorption while elevating blood potassium levels as a potentially concerning side-effect (Schrier et al., 2010).

Similarly, SL prevents aldosterone from binding to endothelial MRs to inhibit vasodilation (Nishizaka et al., 2004). As Nishizaka et al. (2004) describe, aldosterone normally inhibits the expression of endothelial nitric oxide (NO) synthase, an enzyme required to produce NO. NO is a gaseous signalling molecule that dilates blood vessels, and so aldosterone exerts vasoconstrictive effects by inhibiting its synthesis. In turn, SL promotes vasodilation by preventing aldosterone binding, as well as the 
formation of oxygen-anion scavengers of NO (Nishizaka et al., 2004). Nuclear MRs and GRs exert control by regulating the transcription of various genes, which affect the functions of the cell carrying the receptor. However, MRs and GRs can also exert fast, nongenomic effects in response to rising CORT. In these two ways, the receptors modulate hippocampal functions (de Kloet et al., 2005). For example, Yau et al., (1999) note that hippocampal MR activation facilitates long-term potentiation (LTP), while GR activation impairs LTP and facilitates long-term depression. Both LTP and LTD are thought to underlie learning and memory. It is not well understood how these stress-induced changes occur. Regardless, by blocking CORT from binding to MRs, SL causes CORT levels to rise and GR activation to increase (Yau et al., 1999). As a result, SL suppresses excitation and impairs LTP.

SL also acts moderately as a competitive androgen receptor antagonist. By preventing androgens like testosterone from binding at various target tissues, $\mathrm{SL}$ inhibits their effects (Sica, 2005). Furthermore, the active metabolites of SL weakly decrease androgen synthesis by destroying the heme of certain cytochromes P450, such as 17ahydroxylase, which hydroxylates steroids in the adrenal cortex and testes to produce testosterone and its precursors (Menard et al., 1979).

\section{Current Uses of SL}

\section{Current Uses as An Antimineralocorticoid}

SL was patented as a treatment for edema and hypertension due to its antimineralocorticoid activity (Kolkhof \& Barfacker, 2017). As mentioned earlier, aldosterone binds to renal MRs to promote water and sodium reabsorption into the bloodstream (Schrier et al., 2010). However, individuals with cardiac disease, renal disorders, adrenal adenomas, and/or adrenal hyperplasia, often secrete abnormally high levels of aldosterone (Harris et al., 2003). This results in excessive renal MR activation, which causes excessive water retention and expansions in plasma volume, or hypervolemia (Harris et al., 2003). Hypervolemia often manifests as a swelling condition called edema, which is treated using diuretic drugs, like SL, to promote fluid loss through urination (Schrier et al., 2010). SL acts as a diuretic by preventing aldosterone binding, thereby inhibiting the synthesis of channels and transporters that move sodium and water into the ECF (Schrier et al., 2010). It is an effective diuretic, as evidenced in a study by Karalliede et al. (2006), where a fifth of 260 edematous patients was treated with $50 \mathrm{mg} /$ day of SL for a week. Researchers subsequently observed that of three diuretics, SL had the greatest effect, including a mean reduction of $1.00 \mathrm{~L} / 1.73$ $\mathrm{m} 2$ in ECF volume and a mean reduction of $1.09 \mathrm{~kg}$ in body weight (Karalliede et al., 2006). 
Both ECF volume and weight are measures of edema, and their reductions demonstrate SL's efficacy as a diuretic.

As an antimineralocorticoid, $\mathrm{SL}$ is also used to treat hypertension (Kolkhof and Barfacker, 2017). Excess aldosterone contributes to hypertension by binding to both renal and endothelial MRs. As mentioned in the previous paragraph, excessive aldosterone binding at the kidneys causes hypervolemia. Hypervolemia leads to elevations in blood flow and pressure, or secondary hypertension (Harris et al., 2003). These elevations are amplified as excessive aldosterone binding occurs at endothelial cells, thereby inhibiting NO synthesis, and consequently, flow-mediated vasodilation (Nishizaka et al., 2004). Since SL inhibits the consequences of excessive aldosterone binding, it is a useful drug for treatmentresistant hypertension, as shown in a study conducted by Nishizaka et al. (2004). In this study, 30 treatment-resistant patients, 18 of which have high aldosterone levels, were treated with $25 \mathrm{mg} /$ day of SL for 3 months in addition to their existing hypertensive regimen. The addition of SL increased vasodilation in both groups (especially in the high aldosterone group), and significantly reduced blood pressure. In the controls, blood pressure decreased from $157 / 87$ to $131 / 75 \mathrm{~mm} \mathrm{Hg}$, and in the high-aldosterone group, blood pressure decreased from $157 / 95$ to $132 / 78 \mathrm{~mm} \mathrm{Hg}$, indicating SL efficacy (Nishizaka et al., 2004).

\section{Current Uses as An Antiandrogen}

As for its secondary function as an antiandrogen, $\mathrm{SL}$ is commonly used offlabel to treat hyperandrogenism in women and its associated symptoms, which include acne vulgaris, hirsutism, and alopecia (Voegli et al., 2009). Hyperandrogenism, the increased ovarian and adrenal production of androgens, is one of the most prevalent endocrine disorders in the world, affecting $5-10 \%$ of women of reproductive age (Voegli et al., 2009). Its common causes include XYY genotype, congenital adrenal hyperplasia $(\mathrm{CAH})$, polycystic ovarian syndrome (PCOS), and Cushing's syndrome (Zouboulis \& Degitz, 2004). By blocking the effects of androgens (Sica, 2005) and by decreasing their production (Menard, 1979), SL can ameliorate the aforementioned symptoms provided their cause is hormonal. For example, a study conducted on 65 women, half of whom were administered 100 $\mathrm{mg} /$ day of SL for a year, found that noncontrol participants exhibited a mean $36.6 \%$ decrease in hirsutism score along with a small, but significant, decline in free testosterone levels (Kelestimur et al., 2004). As for acne vulgaris, a study conducted on 53 patients treated with 100 $\mathrm{mg} /$ day of $\mathrm{SL}$ for three months found that $85 \%$ exhibited clinical improvements in acne, as well as significant reductions in DHEAS (a testosterone precursor) levels. Despite SL's efficacy as an acne treatment, it is not typically administered to men due to side effects like gynecomastia and 
decreased libido, which are also the result of androgen receptor blockade (Yemisci et al., 2005).

Due to its antiandrogenic activity, $S L$ is also commonly used in transgender therapy for feminization, as evidenced in a study by Angus et al. (2019). In this study, 114 transfeminine individuals were assigned to either estradiol, estradiol and $\mathrm{SL}$, or estradiol and cyproterone acetate (CA) treatments. Compared to the estradiol-only group, which had a mean testosterone level of $10.5 \mathrm{nmol} / \mathrm{L}$, the estradiol and SL group had a significant reduction in testosterone at $2.0 \mathrm{nmol} / \mathrm{L}$. That said, only the other androgen receptor antagonist, CA, brought testosterone to female reference levels at $0.8 \mathrm{nmol} / \mathrm{L}$. This indicates that $\mathrm{SL}$ is highly effective at lowering testosterone levels in transfeminine individuals who have not undergone testes removal, but remains less effective compared to CA. This is because $S L$ only weakly inhibits steroidogenesis, whereas CA does so more strongly. However, CA is associated with depression and $\mathrm{SL}$ with excess diuresis, which must be taken into consideration when choosing between these two (Angus et al., 2019).

\section{Possible Effects on Cognition and Behaviour}

Because MRs modulate hippocampal functions, such as selective attention and visuospatial learning (Yau et al., 1999), SL weakens these cognitive functions by blocking CORT binding. These SL-induced impairments are seen in an experiment conducted by Otte et al. (2007), in which 16 males were given $600 \mathrm{mg}$ of SL and then administered the $\mathrm{d} 2$-test, complex figure tests, and the trail-making test to evaluate attention, visuospatial memory, and mental flexibility. Compared to the placebo group, the SL group performed poorly, indicating impairments in the aforementioned cognitive processes. Similar results have been found in mice, where SL treatment is associated with impaired performance on a visuospatial water-maze task (Yau et al., 1999). However, there was no difference between the $S L$ and placebo group on tests for verbal and working memory, suggesting that hippocampal MRs do not mediate these functions and are therefore unaffected by SL (Otte et al., 2007). As for other types of memory, certain studies also indicate impairments in autobiographical memory (Young et al., 2016) and emotional memory (Rimmele et al., 2013) upon MR blockade by SL.

Given CORT and the MR's role in promoting and maintaining the stress response, $\mathrm{SL}$ is also hypothesized to have an anxiolytic effect by blocking CORT from binding (Bitran et al., 1998). In fact, mice treated intracranially with 0.5 or $1.0 \mathrm{ng}$ of $\mathrm{SL}$ (but not $2.0 \mathrm{ng}$ ) exhibited heightened anxiety-like behaviours when placed in an open field and elevated plus maze (Bitran et al., 1998). However, when Otte et al., (2007) investigated the effects of SL on 
panic symptoms induced by cholecystokinin-tetrapeptide (CCK-4) injection in humans, they observed no attenuation in anxious behaviour. That being said, further study needs to be done before ruling out $S L$ as an anxiolytic in humans. While the MR blockade did not affect chemically induced panic, it may instead work on naturally occurring stress (like in the Bitran et al. 1998 study in mice) or psychosocial stress, which operate under different mechanisms (Otte et al., 2007). Hence, further research should be done on the possible effects of SL on anxiety levels in different situations. Bitran et al., (1998) also observed that anxiolytic effects formed a dosedependent inverted u-shaped curve in mice, suggesting that the dosage in Otte et al. (2007) may have been too high or too low. However, it may be ethically difficult to study whether a similar anxiolytic, dose-dependent curve occurs in humans.

Further research should be done on the cognitive effects of SL in different groups, such as women and the elderly. Many studies conducted on SL in humans, such as the aforementioned Otte et al. (2007), Young et al. (2016), and Rimmele et al. (2013), were conducted in young males only. Females may be excluded because progesterone acts as a functional MR receptor antagonist (Wingenfeld \& Otte, 2019), and estrogen can interfere with MR signalling (Mueller et al., 2014). Hence, it is possible that these hormones would amplify the effects of an MR blockade by SL. Regardless, research should be conducted to investigate whether menstrual cycles or contraceptive-use influence the cognitive effects of such a blockade. Studies in other groups could further elucidate whether MRs play critical roles in selective attention; visuospatial, autobiographical, and emotional memory; and mental flexibility.

\section{Conclusion}

Coming a long way from its early days as a mere diuretic, SL has become a multi-use drug due to the discovery of its (accidental) antiandrogenic effects. As researchers continue to elucidate the role of MRs in cognition and behaviour, new possibilities for $S L$ as an anxiolytic may also emerge. That said, the sexual sideeffects of SL, especially in males, continue to limit its various applications. 


\section{References:}

Abshagen, U., Von Grodzicki, U., Hirscheberger, U., \& Rennekamp, H. (1977). Effect of enterohepatic circulation on the pharmacokinetics of spironolactone in man. NaunynSchmiedeberg's Archives of Pharmacology, $281-287$. https://doi.org/10.1007/BF00500971

Angus, L., Leemaqz, S., Ooi, O., Cundill, P., Silberstein, N., Locke, P., Zajac, J., \& Cheung, A. (2019). Cyproterone acetate or spironolactone in lowering testosterone concentrations for transgender individuals receiving oestradiol therapy. Endocrine Connections, 8(7), 935-940. https://doi.org/10.1530/EC-19-0272

Bitran, D., Sheikh, M., Dowd, J. A., Duhan, M. M., \& Renda, P. (1998). Corticosterone is permissive to the anxiolytic effect that results from the blockade of hippocampal mineralocorticoid receptors. Pharmacology Biochemistry and Behavior, 60(4), 879-887. https://doi.org/10.1016/s0091-3057(98)00071-9

Cashman, J. R., \& Pena, S. (1989). Canrenone formation via general-base-catalyzed elimination of 7.alpha.-(methylthio)spironolactone S-oxide. Chemical Research in Toxicology, 2(2), 109-113. https://doi.org/10.1021/tx00008a007

de Kloet, E., Joëls, M., \& Holsboer, F. (2005). Stress and the brain: From adaptation to disease. Nature Reviews Neuroscience, 6(6), 463-475. https://doi.org/10.1038/nrn1683

Gardiner, P., Schrode, K., Quinlan, D., Martin, B. K., Boreham, D. R., Rogers, Stubbs, K., Smith, M., \& Karim, A. (1989). Spironolactone metabolism: Steady state serum levels of the sulfurcontaining metabolites. Journal of Clinical Pharmacology, 29(4), $342-347$. https://doi.org/10.1002/j.1552-4604.1989.tb03339.x

Harris, D. A., Au-Yong, I., Basnyat, P. S., Sadler, G. P., \& Wheeler, M. H. (2003). Review of surgical management of aldosterone secreting tumours of the adrenal cortex. European Journal of Surgical Oncology, 29(5), 467-474. https://doi.org/10.1016/S0748-7983(03)00051-9

Jankowski, A., Skorek-Jankowska, A., \& Lamparczyk, H. (1996). Simultaneous determination of spironolactone and its metabolites in human plasma. Journal of Pharmaceutical and Biomedical Analysis, 14(8), 1359-1365. https://doi.org/10.1016/S0731-7085(96)01767-0

Karalliedde, J., Buckingham, R., Starkie, M., Lorand, D., Stewart, M., \& Viberti, G. (2006). Effect of various diuretic treatments on rosiglitazone-induced fluid retention. Clinical Journal of the American Society of Nephrology, 17(12), 3482 - 3490. https://doi.org/10.1681/ASN.2006060606 
Kelestimur, F., Everest, H., Unluhizarci, K., Bayram, F., \& Sahin, Y. (2004). A comparison between spironolactone and spironolactone plus finasteride in the treatment of hirsutism. European Journal of Endocrinology, 150(3), 351-354. https://doi.org/10.1530/eje.0.1500351

Kolkhoff, P., \& Barfacker, L. (2017). 30 years of the mineralocorticoid receptor. Journal of Endocrinology, 234(1), 125 -140. https://doi.org/10.1530/JOE-16-0600

Menard, J. (2004). The 45-year story of the development of an anti-aldosterone more specific than spironolactone. Molecular and Cellular Endocrinology, 217(2), 45-52. https://doi.org/10.1016/j.mce.2003.10.008

Menard, R. H., Guenthner, T. M., Kon, H., \& Gilette, J. R. (1979). Studies on the destruction of adrenal and testicular cytochrome P-450 by spironolactone. The Journal of Biological Chemistry, 254(5), 1726-1733.

Barrett Mueller, K., Lu, Q., Mohammad, N. N., Luu, V., McCurley, A., Williams, G. H., Adler, G. K., Karas, R. H., \& Jaffe, I. Z. (2014). Estrogen receptor inhibits mineralocorticoid receptor transcriptional regulatory function. Endocrinology, 155(11), 4461-4472. https://doi.org/10.1210/en.2014-1270

Nishizaka, M. K., Zaman, M. A., Green, S. A., Renfroe, K. Y., \& Calhoun, D. A (2004). Impaired endothelium-dependent flow-mediated vasodilation in hypertensive subjects with $\begin{array}{lll}\text { hyperaldosteronism. Circulation, } & \text { 109(23), }\end{array}$ https://doi.org/10.1161/01.CIR.0000129307.26791.8E

Otte, C., Moritz, S., Yassouridis, A., Koop, M., Madrischewski, A. M., Wiedemann, K., \& Kellner, M. (2007). Blockade of the mineralocorticoid receptor in healthy men: Effects on experimentally induced panic symptoms, stress hormones, and cognition. Neuropsychopharmacology, 32(1), 232-238. https://doi.org/10.1038/sj.npp.1301217

Overdiek, H. W., \& Merkus, F. W. (1986). Influence of food on the bioavailability of spironolactone. Clinical Pharmacology Therapy, 40(5), $531-536$. https://doi.org/10.1038/clpt.1986.219

Rimmele, U., Besedovsky, L., Lange, T., \& Born, J. (2013). Blocking mineralocorticoid receptors impairs, blocking glucocorticoid receptors enhances memory retrieval in humans. Neuropsychopharmacology, 38(5), 884-894. https://doi.org/10.1038/npp.2012.254 
Sica, D. A. (2005). Pharmacokinetics and pharmacodynamics of mineralocorticoid blocking agents and their effects on potassium homeostasis. Heart Failure Reviews, 10(1), $23-29$. https://doi.org/10.1007/s10741-005-2345-1

Schrier, R.W., Masoumi, A., \& Elhassan, Elwaleed. (2010). Aldosterone: Role in edematous disorders, hypertension, chronic renal failure, and metabolic syndrome. Clinical Journal of the American Society of Nephrology, 5(6), 1132-1140. https://doi.org/10.2215/CJN.01410210

Takamura, N., Maruyama, T., Ahmed, S., Suenaga, A., \& Otagiri, M. (1997). Interactions of aldosterone antagonist diuretics with human serum proteins. Pharmaceutical Research, 14(4), 522 - 526. https://doi.org/10.1023/a:1012168020545

Voegeli, S. K., Rey, F., Reymond, M. J., Meuwly, J., Gaillard, R. C., \& Gomez, F. (2009). Androgen dependence of hirsutism, acne, and alopecia in women: Retrospective analysis of 228 patients investigated for hyperandrogenism. Medicine, 88(1), $32-45$. https://doi.org/10.1097/md.0b013e3181946a2c

World Health Organization. (2019). World Health Organization model list of essential medicines: 21st list 2019. https://apps.who.int/iris/handle/10665/325771

Wingenfeld, K., \& Otte, C. (2019). Mineralocorticoid receptor function and cognition in health $\begin{array}{llll}\text { and disease. Psychoneuroendocrinology, } & \text { 105, }\end{array}$ https://doi.org/10.1016/j.psyneuen.2018.09.010

Yau, J. L. W., Noble, J., \& Seckl, J. R. (1999). Continuous blockade of brain mineralocorticoid receptors impairs spatial learning in rats. Neuroscience Letters, 277(1), 45-48. https://doi.org/10.1016/S0304-3940(99)00858-7

Yemisci, A., Gorgulu, A., \& Piskin, S. (2005). Effects and side-effects of spironolactone therapy in women with acne. European Journal of Dermatology and Venereology, 19(2), 163-166. https://doi.org/10.1111/j.1468-3083.2005.01072.x

Young, K. D., Preskorn, S. H., Victor, T., Misaki, M., Bodurka, J., \& Drevets, W. C. (2016). The effect of mineralocorticoid and glucocorticoid receptor antagonism on autobiographical memory recall and amygdala response to implicit emotional stimuli. International Journal of Neuropsychopharmacology, 19(9), 1-11. https://doi.org/10.1093/ijnp/pyw036

Zouboulis, C. C., \& Degitz, K. (2004). Androgen action on human skin - from basic research to clinical significance. Experimental Dermatology, 13(4), 5-10. https://doi.org/10.1111/j.16000625. 2004.00255.x 